\title{
THE APPLICATION OF THE BSSD IONO-FREE LINEAR COMBINATION METHOD IN THE PROCESSING OF AIRCRAFT POSITIONING
}

\author{
Janusz Ćwiklak, Marek Grzegorzewski, Kamil Krasuski \\ Polish Air Force University \\ Faculty of Aviation, Department of Air Navigation \\ Dywizjonu 303 Street 35, 08-521 Deblin, Poland \\ tel.: +48261517412, +48261517423, +48261517133 \\ e-mail:j.cwiklak@law.mil.pl,m.grzegorzewski@law.mil.pl,k.krasuski@law.mil.pl
}

\begin{abstract}
The article presents the results of research into the use of the differentiation technique of BSSD (Between Satellite Single Difference) observations for the Iono-Free LC combination (Linear Combination) in the GPS system for the needs of aircraft positioning. Within the conducted investigations, a positioning algorithm for the BSSD Iono-Free LC positioning method was presented. In addition, an experimental test was conducted, in which raw observational data and GPS navigation data were exploited in order to recover the aircraft position. The examination was conducted for the Cessna 172 and the on-board dual-frequency receiver Topcon HiperPro. The experimental test presents the results of average errors of determining the position of the Cessna 172 in the XYZ geocentric frame and in the ellipsoidal BLh frame. Furthermore, the article presents the results of DOP (Dilution of Precision) coefficients, the test of the Chi square internal reliability test and the HPL and VPL confidence levels in GNSS precision approach (PA) in air transport. The calculations were performed in the original APS software (APS Aircraft Positioning Software) developed in the Department of Air Navigation of the Faculty of Aeronautics at the Polish Air Force University.
\end{abstract}

Keywords: GPS system, aircraft positioning, BSSD Iono-Free linear combination, air navigation

\section{Introduction}

The use of dual-frequency navigation receivers in aviation brings numerous benefits [1], primarily in terms of widely understood air navigation. First of all, the most important role is to determine the position of the aircraft in a three-dimensional coordinate frame, usually the Cartesian XYZ coordinate frame or the ellipsoidal BLh frame. The dual-frequency GNSS receiver provides the use of code or phase observations on L1 and L2 frequencies in navigation computations [2]. Therefore, the number of observations used in the computations is two-fold. Furthermore, dual-frequency observations allow the creation of measurement values referred to as linear combinations of GNSS observations. In air navigation, code measurements for precise positioning of aircraft are mainly used. In case of dual-frequency code observations, it is possible to make a mathematical formulation of the Ion-Free linear combination [3], which is used to determine the aircraft coordinates. Besides, it is possible to differentiate GNSS observations in the Iono-Free linear combination. Such a positioning technique is referred to as the BSSD IonoFree LC.

The aim of this article is to make a practical application of the BSSD Iono-Free LC positioning method in air navigation. The BSSD Iono-Free LC research method has found a practical application to calculate the aircraft position. The BSSD Iono-Free LC positioning technique may be widely used in the GPS and GLONASS navigation system in aviation.

\section{The mathematical model of the BSSD Iono-Free LC in the GPS system - Research test}

The basic observation equation in the BSSD Iono-Free LC positioning technique can be expressed as below [4]: 


$$
\Delta P_{3}=\Delta d_{i j}-c \cdot \Delta d t s_{i j}+\Delta T_{i j}+\operatorname{Rel}_{i j}+\Delta M p_{i j}
$$

where:

$\Delta$ - operator of single difference technique,

$P_{3}$ - the Iono-Free linear combination for GPS code observations,

$$
\Delta P_{3}=\alpha_{1} P_{1 i}+\alpha_{2} P_{2 i}-\alpha_{1} P_{1 j}-\alpha_{2} P_{2 j},
$$

$\left(\alpha_{1}, \alpha_{2}\right)$ - linear coefficients,

$\left(P_{1}, P_{2}\right)-$ code observations at $1^{\text {st }}$ and $2^{\text {nd }}$ frequency in the GPS system,

$i \quad-$ index of $i$-th satellite,

$j \quad-$ index of $j$-th satellite,

$d \quad-$ geometric distance between satellite and on-board receiver,

$$
d=\sqrt{\left(X-X_{S}\right)^{2}+\left(Y-Y_{S}\right)^{2}+\left(Z-Z_{S}\right)^{2}},
$$

$(X, Y, Z) \quad$ - coordinates of the aircraft in $X Y Z$ geocentric frame,

$\left(X_{S}, Y_{S}, Z_{S}\right)$ - satellite coordinates in GPS system,

$c \quad-$ speed of light,

$d t s \quad-$ satellite clock bias correction,

Trop - tropospheric delay,

Rel - relativistic effect,

Mp - multipath effect for GPS code observations.

The coordinates of the aircraft from equation (1) are determined by the least squares stochastic process, including a matrix of weights and average error measurements. The computations of the aircraft position were made by means of the APS software, developed at the Department of Air Navigation in Deblin. The APS programme was written in the language environment Scilab 6.0.0 as an "open-source"-type application. The computations exploited real observations and navigation data from an on-board GPS receiver mounted in a Cessna 172. The Cessna 172 executed a flight around the aerodrome in Deblin. The receiver recorded dual-frequency GPS code observations every second. During the calculations in the APS programme in the post-processing, the following input parameters were set [5]:

- GNSS system: GPS system,

- type of observations: code observations at $1^{\text {st }}$ and $2^{\text {nd }}$ frequency in the GPS system,

- type of RINEX file: 2.10 ,

- source of satellite ephemeris data: precise ephemeris from the IGS service,

- source of satellite clock data: precise ephemeris from the IGS service,

- method of satellite position computation: 9-degrees Lagrange polynomial,

- method of satellite clock bias computation: 9-degrees Lagrange polynomial,

- effect of Earth rotation and time of pseudorange travelling through atmosphere: applied,

- relativistic effect: applied,

- troposphere source: Simple model,

- receiver clock bias: estimated,

- multipath and measurement noise: not applied,

- satellite and receiver phase centre offset: based on ANTEX file from IGS service,

- Sagnac effect: applied,

- cut-off elevation: $5^{\circ}$,

- a priori standard deviation of pseudorange observations: $1 \mathrm{~m}$,

- positioning mode: kinematic,

- mathematical model of solution: least square estimation in iterative scheme,

- adjustment processing: applied,

- maximum number of iterations in a single measurement epoch: $N=10$,

- number of unknown parameters: $k=3$ for each measurement epoch, 
- number of observations: $n>3$ for each measurement epoch,

- interval of computations: $1 \mathrm{~s}$,

- initial coordinates of aircraft position: based on header of RINEX file,

- time of GPS system: GPS Time,

- reference frame: IGS 08,

- format of output coordinates geocentric XYZ and ellipsoidal BLh,

- local test of residuals: applied,

- global statistical test: test Chi square,

- significance level: $(1-\alpha)=0.95$,

- DOP coefficients: estimated,

- coefficients value for HPL and VPL level: $k_{H P L}=6.18$ and $k_{V P L}=5.33$.

\section{Results and discussion}

Within the conducted calculations carried out in the APS software, the following output parameters were specified: average errors of designating the aircraft coordinates in the XYZ geocentric frame and the ellipsoidal BLh frame, the resultant average error of the MRSE position in 3D space, the dilution of precision (DOP) coefficients (HDOP, VDOP, GOP, PDOP), the statistical values of the global Chi square reliability test and the HPL and VPL reliability levels in air transport.

Figure 1 shows the results of average errors in determining the aircraft coordinates in the geocentric $X Y Z$ frame. The maximum value of the aircraft average position along the $X$-axis equals $12.8 \mathrm{~m}$, along the $Y$-axis, it is $4.6 \mathrm{~m}$, and along the $Z$-axis, it is $13.9 \mathrm{~m}$. It needs to be emphasized that the usual value of average errors of an aircraft position in the $X Y Z$ coordinate frame is approximately $1.6 \mathrm{~m}, 0.9 \mathrm{~m}, 1.9 \mathrm{~m}$, respectively.

Figure 2 shows the results of average errors in determining the aircraft coordinates in the ellipsoidal $B L h$ frame. The maximum error value of the average position of the aircraft for the geodetic latitude $B$ is $13.6 \mathrm{~m}$. For the geodetic longitude $L$, it is $3.6 \mathrm{~m}$, and for the ellipsoidal height $h$, it is $13.4 \mathrm{~m}$. It should be stressed that the usual value of mean errors in the aircraft position in the ellipsoidal BLh frame equals approximately $1.3 \mathrm{~m}, 0.8 \mathrm{~m}, 2.1 \mathrm{~m}$.

Figure 3 shows the results of the resultant error MRSE [6] in designating the aircraft coordinates. The maximum value of the MRSE error in determining the aircraft position is $19.4 \mathrm{~m}$. It is necessary to emphasize the fact that the average value of the MRSE error in an aircraft position equals $2.6 \mathrm{~m}$. In addition, the MRSE error in an aircraft position is identical in the $X Y Z$ geocentric frame and in the $B L h$ frame.

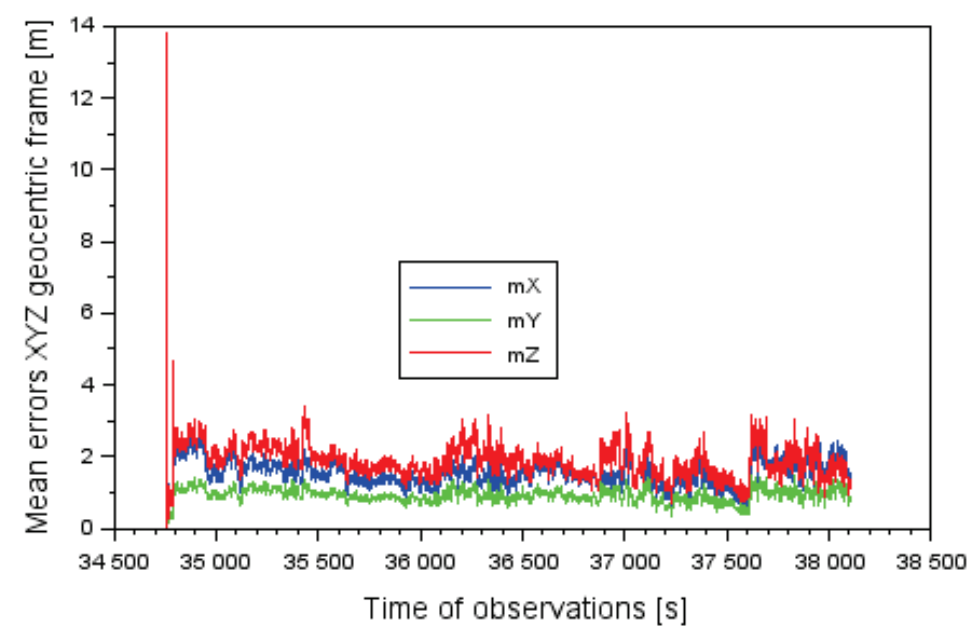

Fig. 1. Mean errors of aircraft position in the XYZ geocentric frame 


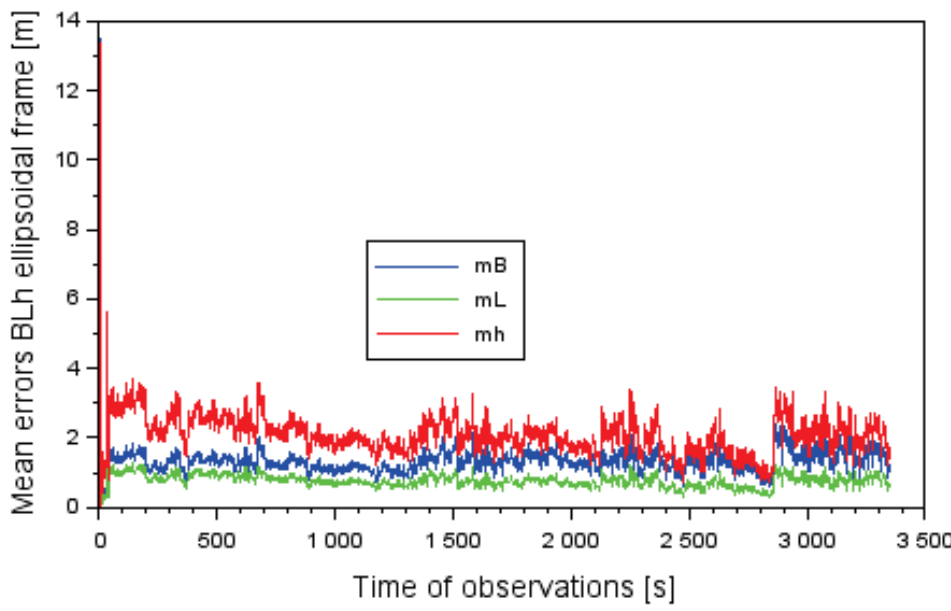

Fig. 2. Mean errors of aircraft position in the BLh ellipsoidal frame

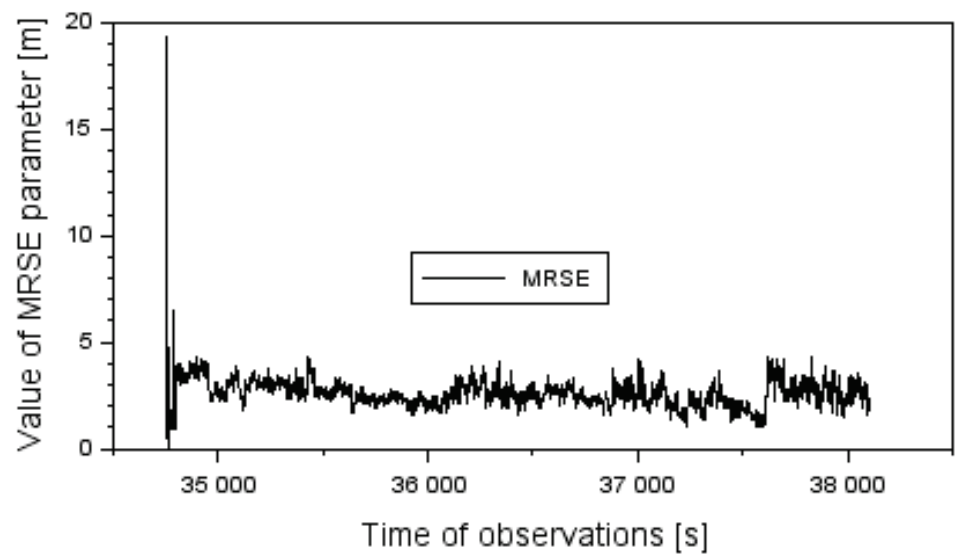

Fig. 3. Results of the MRSE parameter

Figure 4 shows the results of dilution of precision (DOP) coefficients as HDOP, VDOP, GDOP, PDOP parameters [7]. The values of the HDOP parameter range from 1.0 to 13.8 . Moreover, the values of the VDOP parameter are expressed by the results ranging from 0.7 to 13.7. The values of the PDOP parameter are expressed by the results ranging from 1.4 to 14.3 . The values of the GDOP parameter range from 1.5 to 14.8. The average values of HDOP, VDOP, PDOP and GDOP coefficients are 1.4, 1.9, 2.0 and 2.3, respectively.

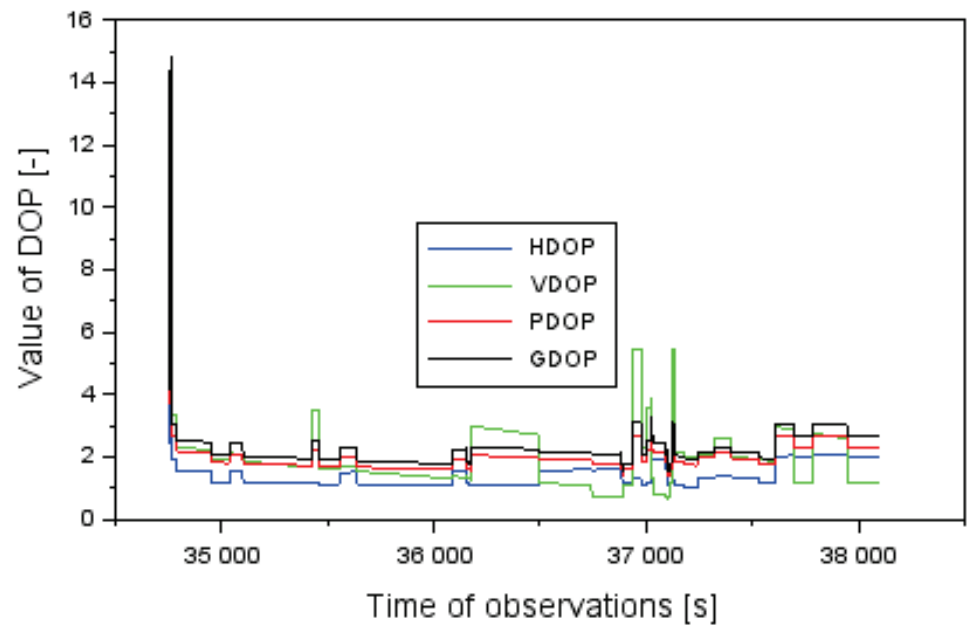

Fig. 4. Results of DOP coefficients 
Figure 5 shows the results of the statistical Chi-square test at a confidence level of 0.95 , and the number of freedom degrees $f=n-k$ equal to [8]. The values of the PVV variable range from 3.3 to 33.0, respectively. Then, the tabular values of the Chi square test range between 7.8 and 47.4. Based on the obtained findings, the global chi square test was fulfilled at a confidence level of 0.95 . Therefore, the process of adjustment of GPS observations was executed properly.

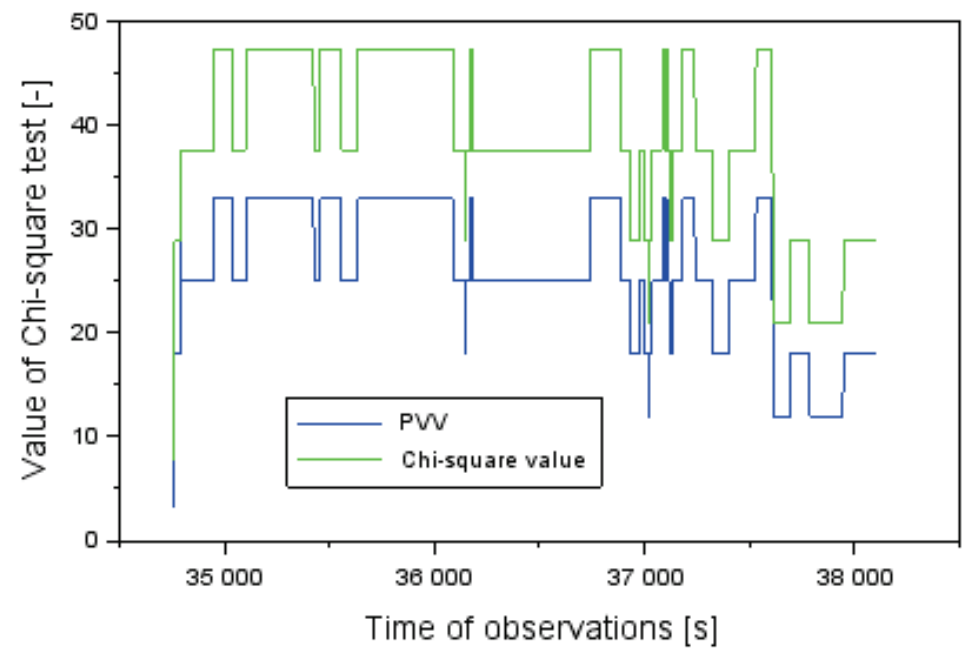

Fig. 5. Results of Chi square test

Figure 6 presents the results of the HPL and VPL reliability levels [9] obtained in the BSSD Iono-Free LC positioning method. The maximum findings of the HPL parameter equal up to $86.6 \mathrm{~m}$, and for the VPL parameter, they are equal to $71.4 \mathrm{~m}$. Besides, the mean value of the HPL parameter is equal to $9.5 \mathrm{~m}$, while of the VPL parameter, it is equal to $11.1 \mathrm{~m}$, respectively. In accordance with the ICAO requirements, the HPL values in PA must range from $40 \mathrm{~m}$ to $50 \mathrm{~m}$ (the so-called HAL critical alert) [10]. Apart from the results in the initial 10 measurement epochs, the HPL values are lower than the critical HAL level. Besides, in compliance with the ICAO requirements, the VPL values in (PA) precision approach must be between $10 \mathrm{~m}$ and $20 \mathrm{~m}$ (the socalled VAL critical alert [10]. Apart from the results of the initial 20 measurement epochs, the VPL values are lower than the critical VAL level.

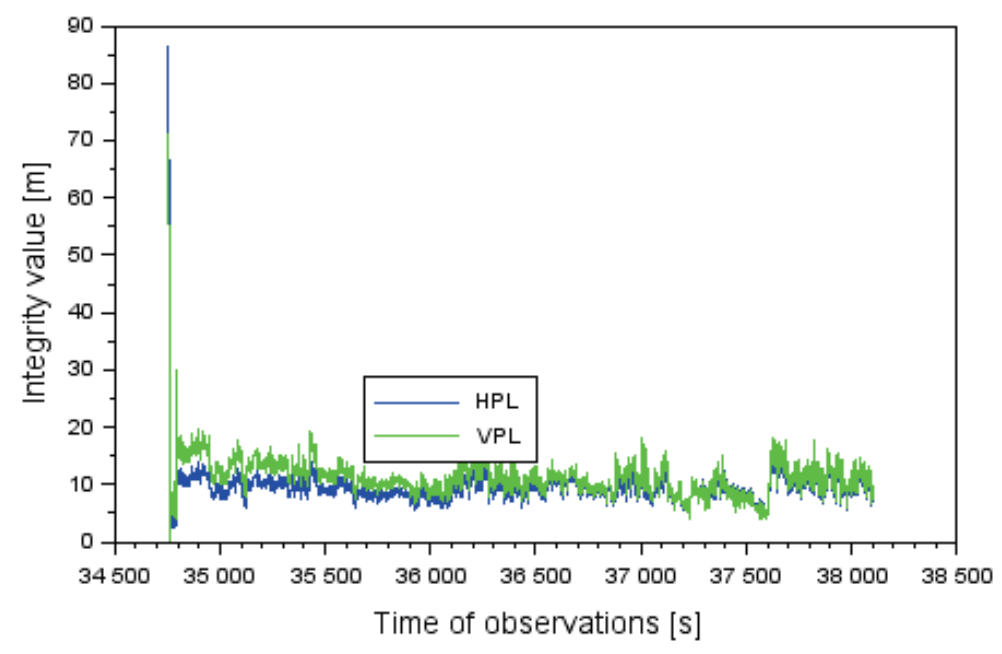

Fig. 6. Results of integrity for HPL and VPL terms

Figure 7 shows the number of GPS satellites used in the computations within the BSSD IonoFree LC method. The number of GPS satellites varies from 4 to 9 during the research test. 
In addition, the average number of GPS satellites during the experimental test equalled 8 . The integrity of tracking satellites in the GPS constellation was maintained, which is extremely crucial in air navigation.

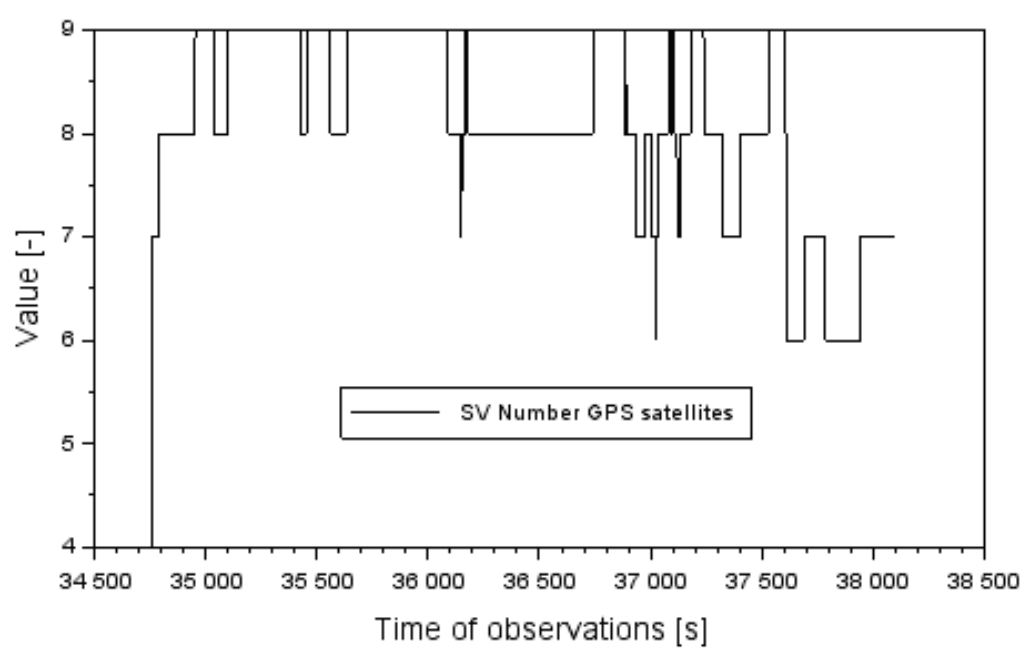

Fig. 7. Total number of GPS satellites in the flight test

\section{Conclusions}

The article publishes the research results of the BSSD Iono-Free LC method for dual-frequency GPS code observations in aeronautical applications. The computations exploited real observation and navigation GPS data from an on-board GNSS receiver mounted in the Cessna 172. All the simulations and computations were made in the APS special software, developed by researchers in the Department of Air Navigation of the Aeronautics Faculty of the Polish Air Force University. The authors of the paper presented the following parameters: mean errors of designating the aircraft coordinates in the $X Y Z$ geocentric frame and the ellipsoidal BLh frame, the resultant mean error of the MRSE position in 3D space, the dilution of precision coefficients DOP (HDOP, VDOP, GOP, PDOP), the statistical values of the global Chi square test and the HPL and VPL reliability levels in air transport. On the basis on the obtained results of the investigations, it was found that:

- the mean errors of determining the aircraft coordinates do not exceed $14 \mathrm{~m}$,

- the statistical Chi square test at a confidence level of 0.95 was met,

- the average values of DOP coefficients are lower than 2.3,

- the average values of the HPL/VPL reliability levels do not exceed $12 \mathrm{~m}$.

The method of research presented in this paper finds a practical application in aircraft precise positioning. Thus, the test results for this method are interesting from the standpoint of the implementation of the GNSS satellite technology in aviation. The described research method may be used in the GPS, GLONASS and GPS/GLONASS navigation solutions.

\section{References}

[1] Oszczak, B., Kondratowicz, S., A controller of a dual-frequency GNSS receiver, TRANSCOMP - XIV International Conference Computer Systems Aided Science, Industry and Transport, Logistyka, No. 6, pp. 2595-2600, 2010.

[2] Przestrzelski, P., Bakuła, M., Tanajewski, D., Differential code GPS+GLONASS positioning, Logistyka, No. 3, pp. 5323-5329, 2014.

[3] Bosy, J., Precise processing of satellite GPS observations in local networks located in mountain areas, Zeszyty Naukowe Akademii Rolniczej we Wrocławiu, Wydawnictwo 
Akademii Rolniczej we Wrocławiu, No. 522, 2005.

[4] Afifi, A., El-Rabbany, A., Performance Analysis of Several GPS/Galileo Precise Point Positioning Models, Sensors, Vol. 15, pp. 14701-14726, 2015.

[5] Krasuski, K., Aircraft positioning using SPP method in GPS system, Aircraft Engineering and Aerospace Technology, Vol. 90, Iss. 8, pp. 1213-1220, 2018.

[6] Seeber, G., Satellite Geodesy - 2nd completely revised and extended edition, Walter de Gruyter GmbH \& Co. KG, 10785 Berlin, Germany 2003.

[7] Śledziński, J., Satelitarny system wyznaczania pozycji $w$ geodezji i nawigacji $-c z$. VI, Błędy geometrii i technologii, NAWI, 6/2005 (8), pp. 3-4, 2005.

[8] Schüler, T., On ground-based GPS tropospheric delay estimation, $\mathrm{PhD}$ thesis, Heft 73, Universität der Bundeswehr München, Germany 2001.

[9] Ciećko, A., Grunwald, G., Examination of autonomous GPS and GPS/EGNOS integrity and accuracy for aeronautical applications, Periodica Polytechnica Civil-Engineering, Vol. 61 (4), pp. 920-928, 2017.

[10] International Civil Aviation Organization, ICAO Standards and Recommended Practices (SARPS), Annex 10, Volume I (Radionavigation aids), 2006, Polsih version available on: http://www.ulc.gov.pl/pl/prawo/prawomi\%C4\%99dzynarodowe/206-konwencje, of 15.10.2018. Manuscript received 24 June 2019; approved for printing 26 September 2019 